\title{
Post-Orthodontic Lower Incisors Recessions: Combined Periodontic and Orthodontic Approach
}

\author{
Ilan Beitlitum ${ }^{1}$, Vered Barzilay ${ }^{2}$, Fatma Rayyan ${ }^{3}$, Alon Sebaoun ${ }^{1}$ and Rachel Sarig $2,3,4, *,+$ (i) \\ 1 Department of Periodontology and Dental Implantology, The Maurice and Gabriela Goldschleger School \\ of Dental Medicine, Sackler Faculty of Medicine, Tel Aviv University, Tel Aviv 6997801, Israel; \\ beilan1@bezeqint.net (I.B.); alon.sebaoun@gmail.com (A.S.) \\ 2 Department of Orthodontics, The Maurice and Gabriela Goldschleger School of Dental Medicine, \\ Sackler Faculty of Medicine, Tel Aviv University, Tel Aviv 6997801, Israel; vered.barzilay@gmail.com \\ 3 Department of Oral Biology, The Maurice and Gabriela Goldschleger School of Dental Medicine, \\ Sackler Faculty of Medicine, Tel Aviv University, Tel Aviv 6997801, Israel; fatma_rayyan@hotmail.com \\ 4 The Dan David Center for Human Evolution and Biohistory Research, Sackler Faculty of Medicine, \\ Tel-Aviv University, Tel Aviv 6997801, Israel \\ * Correspondence: sarigrac@tauex.tau.ac.il; Tel.: +972-3-640-6569 \\ + Current address: The Goldschleger School of Dental Medicine, Sackler Faculty of Medicine, \\ Tel Aviv University, Tel Aviv 69978, Israel.
}

Received: 9 September 2020; Accepted: 27 October 2020; Published: 2 November 2020

\begin{abstract}
The bonded lingual retainer (BLR) is considered a favorable choice for retaining lower incisors' alignment post-orthodontic treatment; however, it may cause some unwanted effects such as inadvertent tooth movement and torque changes. These often result in gingival recession (Miller class III-type) with exposure of the root surface, which compromises the esthetics and hinders the comfort of the patient. Fifteen post-orthodontic patients presenting Miller class III-type recessions with BLR were examined. Two protocols were used: the first included the removal of the BLR prior to surgery and the second included only a surgical approach. All patients underwent the same surgery of a modified tunnel double papilla procedure for root coverage. The gingival recession was measured using a dental probe before, and three to six months post-surgery. The average improvement in recession depth was significantly greater $(p=0.008)$ for the protocol that included removal of the BLR $(4.0 \pm 0.83 \mathrm{~mm})$ with an improvement of $87.2 \%$ as compared to the second protocol that showed an improvement of $43.8 \%(1.88 \pm 1.29 \mathrm{~mm})$. Removing the BLR prior to surgery is beneficial for predictable root coverage in post-orthodontic Miller class III recessions.
\end{abstract}

Keywords: lingual retainer; gingival recession; connective tissue graft; orthodontics; root coverage

\section{Introduction}

Long-term stability is one of the main challenges of orthodontic treatment [1,2]. Several protocols were suggested to maintain the alignment of mandibular canines and incisors at the end of the active phase of orthodontic treatment $[3,4]$. The protocol of choice for most orthodontists is the bonded lingual retainer (BLR) (reported by $83 \%$ of the orthodontists asked) [5], since it is invisible, independent of patient cooperation and is aimed at lifelong retention.

Although BLR is widely used and has many benefits, it is prone to failures [6] and adverse negative effects, such as localized tooth movement, torque changes, and gingival recessions [6,7]. Long-term BLR follow up and maintenance by either the orthodontist or the treating general dental practitioner is crucial for long-term stability of the orthodontic treatment result and the health of the supporting periodontal tissues [8]. Therefore, all patients must be informed at the end of treatment about the need for frequent follow up visits as long as the BLR is bonded. 
Gingival recession is defined as the displacement of the gingival margin apical to the cemento-enamel junction (CEJ) with exposure of the root surface to the oral environment [9]. Miller's classification of gingival recessions is based on the presence or absence of keratinized tissue at the apical extent of the defect, proximal bone support, and the location of the tooth [10]. Miller's class III is defined as marginal tissue recession, which extends to, or beyond the muco-gingival junction, either due to bone or soft tissue loss in the interdental area or due to malpositioning of the tooth. The main challenge of mucogingival therapy in Miller class III recessions is to obtain full root coverage.

It was suggested that different surgical procedures will provide a significant reduction in recession depth and root coverage of Miller class I and II tooth recession defects [10]; however, no coverage or only partial coverage can be expected in class III and IV defects [11].

The development of gingival recession during orthodontic treatment is associated with mechanics causing tooth movement out of its alveolar envelope (i.e., expansion, proclination or retroclination) [12,13]. However, a recent systematic review indicated that orthodontic treatment did not necessarily affect the development of gingival recession of mandibular incisors [14]. Yet, the etiology is different in the case of post-orthodontic movements. In these cases, inadvertent tooth movement might be caused by a non-passive retainer, distortion of the BLR during the bonding of a passive retainer, or by deformation of the BLR used for retention due to biting forces on hard foods or a consistent habit leading to activation of the retainer's wire $[8,15]$.

A cohort study on the development of labial gingival recessions in orthodontically treated patients, conducted by Renkema et al. [16], found that the prevalence of the labial gingival recessions increases with age and with the time passed since the retention period starting point. The study shows gingival recessions in $20 \%$ of the patients two years post-treatment and in $38 \%$ of the patients five years post-treatment.

The successful outcome of the root coverage procedure is to achieve stable gingival margin coronal to the cemento-enamel junction (CEJ), and soft tissue integration with adjacent tissue [17].

Moreover, treating Miller class III recessions should be aimed at achieving a satisfactory esthetic outcome for the patient and to resolve any hypersensitivity present with minimal patient morbidity [17-19].

Thus, the aim of this study was to explore the benefit of a combined periodontic-orthodontic approach to resolve Miller class III gingival recessions in post-orthodontic patients.

\section{Materials and Methods}

Fifteen cases from the periodontics department at Tel Aviv University were reviewed-all underwent orthodontic treatment and had a BLR on the day of the first examination. The study was approved by the ethical committee of Tel Aviv University (Authorization number 0001732-3). The cases were divided into two groups according to the protocol used: the first included removal of the BLR prior to surgery and a removable retainer was applied to the patient three months after surgery for night-use only (Figure 1). The second protocol did not include BLR removal, only a surgical approach (Figure 2). All patients underwent the same surgical procedure as detailed below (Figure 1). Prior to surgery, occlusal adjustments were made if needed to prevent traumatic occlusal forces. The gingival recession was measured using a North Carolina periodontal probe (UNC-15, Hu-Friedy, Chicago, IL, USA) before the surgery, and three to six months after. Vertical recession was measured at the mid-buccal aspect of the tooth from the cemento-enamel junction (CEJ) to the gingival margin. All cases were documented and photographed using a Canon d-70 camera. 

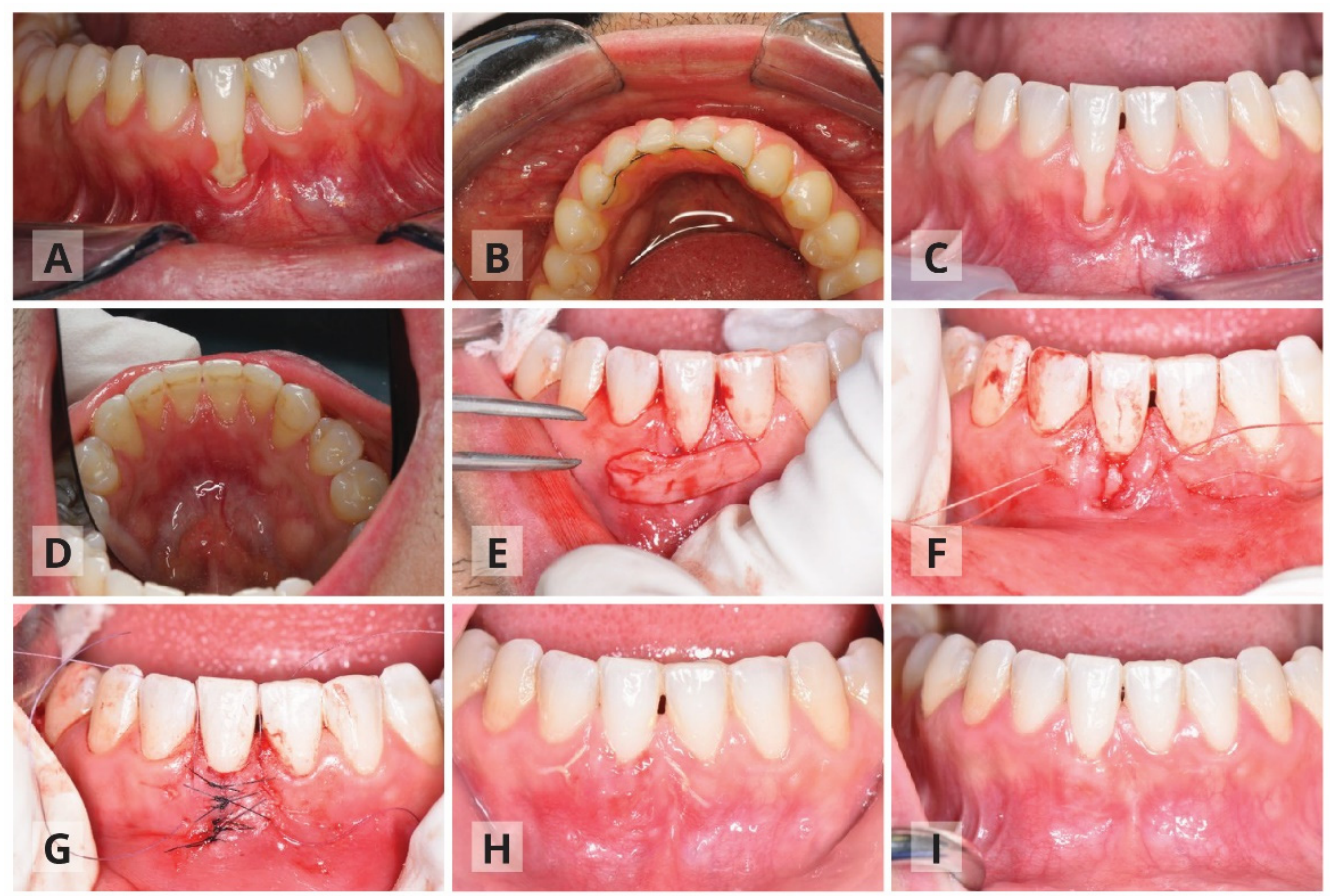

Figure 1. First protocol, which included bonded lingual retainer removal. Patient number thirteen-thirty-one-year-old male arrived with Miller class III recession in tooth \#41. Ten years post-orthodontic treatment, with bonded lingual retainer present $(\mathbf{A}, \mathbf{B})$. Three months after removal of the bonded lingual retainer and prior to surgery $(\mathbf{C}, \mathbf{D})$. During the surgery, the tunneling procedure that includes insertion of connective tissue graft $(\mathbf{E}, \mathbf{F})$. Double papilla suturing and addition of coronal anchoring sutures $(\mathbf{G})$. Gingival healing two weeks post-surgery $(\mathbf{H})$ and three months post-surgery $(\mathbf{I})$.
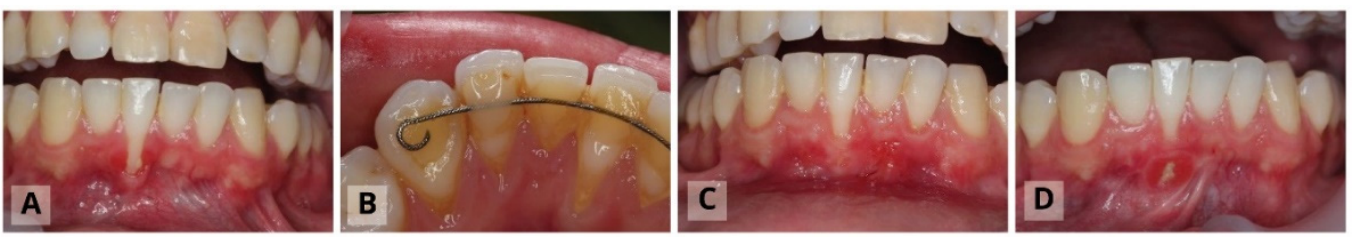

Figure 2. Second protocol-without bonded lingual retainer (BLR) removal. Patient number three-27-year-old male arrived with Miller Class III recessions both on the buccal and the lingual surfaces of tooth \#41. Eight years passed since orthodontic treatment completion and lingual fixed retainer was maintained. Lingual retainer was not removed prior to surgery $(\mathbf{A}, \mathbf{B})$. One month after surgery a gingival recession of $3 \mathrm{~mm}$ was present (C). Six months follow up after surgical procedure, note the gingival fenestration (D).

\section{The Surgical Procedure: Modified Tunnel Double Papilla Procedure for Root Coverage}

Composite flow $(3 \mathrm{M})$ was applied on the contact points mainly for the anchorage of the sutures and the coronally positioned flap, and to avoid unwanted tooth movements. The surgical procedure is detailed briefly; a partial thickness tunnel was prepared. The tunnel extended 3-4 $\mathrm{mm}$ apically beyond the muco-gingival junction and to the recession's adjacent teeth mesially and distally, while undermining the facial aspect of the interdental papilla. The goal was to join the two edges of the recession with no tension and to allow easy coronal displacement of the flap. A connective tissue graft (CTG) was harvested according to Hürzeler and Weng [20] (Figure 1E,F). The connective tissue was inserted and stabilized with resorbable sutures and the two edges of the gingival recession were then approximated to be tension free, with simple interrupted sutures starting from the apical part of the recession. These sutures allow primary soft tissue closure over the connective tissue graft (Figure 1G). Buccal and lingual vertical sutures were added over the temporary splinted teeth for coronally flap positioning. 
The post-operative instructions included rinsing with $0.2 \%$ chlorhexidine (CHX) solution twice a day for two weeks; no anti-inflammatory medication was prescribed and patients were instructed to take analgesics of their preference when needed. Teeth brushing in the surgical area was discontinued during the first post-operative two weeks. Patients were instructed gradually to brush the area with an ultra-soft brush soaked in $0.2 \mathrm{CHX}$ for another 2-6 weeks. Follow up was conducted once a week during the first two months, and professional tooth cleaning was also advised.

The surgical procedure was classified as successful if a reduction in the gingival recession was noted.

The statistical analysis was carried out using SPSS software for Windows (version 20; SPSS, Chicago, IL, USA) and significance level was set for $p=0.05$. Non-parametric analysis (Mann-Whitney) was used to explore differences between the two studied groups.

\section{Results}

Out of the 15 cases that were analyzed, the first protocol that included removal of the BLR was applied to six patients and the second protocol was applied to the other nine patients (Table 1). There was no significant difference in the average age of the patients $(p=0.224)$ or the initial recession depth $(p=0.529)$ between the two groups.

Table 1. Description of patients who attended the study, including recessions depth (in $\mathrm{mm}$ ) before and after the surgery. Recession type following Cairo et al. [17].

\begin{tabular}{|c|c|c|c|c|c|c|c|c|}
\hline \multirow[b]{2}{*}{$\begin{array}{l}\text { Patient } \\
\text { Number }\end{array}$} & \multirow[b]{2}{*}{ Gender } & \multirow[b]{2}{*}{ Age } & \multirow[b]{2}{*}{$\begin{array}{l}\text { Tooth } \\
\text { Number }\end{array}$} & \multirow[b]{2}{*}{$\begin{array}{l}\text { Bonded } \\
\text { Lingual } \\
\text { Retainer } \\
\text { Removal }\end{array}$} & \multicolumn{4}{|c|}{ Recession Depth } \\
\hline & & & & & $\begin{array}{l}\text { Recession } \\
\text { Type }\end{array}$ & $\begin{array}{c}\text { First } \\
\text { Examination } \\
(\mathrm{mm})\end{array}$ & $\begin{array}{c}\text { After } \\
\text { Surgery } \\
(\mathrm{mm})\end{array}$ & $\begin{array}{c}\text { Improvement } \\
(\%)\end{array}$ \\
\hline 1 & Male & 37 & 32 & no & 1 & 6 & 1 & 83.33 \\
\hline 2 & Male & 30 & 41 & no & 2 & 3 & 0.5 & 83.33 \\
\hline 3 & Male & 27 & 41 & no & 1 & 5 & 3 & 40 \\
\hline 4 & Female & 30 & 31 & no & 1 & 4 & 2.5 & 37.5 \\
\hline 5 & Female & 25 & 31 & no & 2 & 4 & 3 & 25 \\
\hline 6 & Female & 42 & 31 & no & 2 & 4 & 3 & 25 \\
\hline 7 & Male & 28 & 31 & no & 1 & 4 & 2 & 50 \\
\hline 8 & Female & 25 & 31 & no & 1 & 4 & 3 & 25 \\
\hline 9 & Female & 28 & 31 & no & 1 & 4 & 3 & 25 \\
\hline 10 & Female & 32 & 41 & yes & 1 & 4 & 0 & 100 \\
\hline 11 & Female & 56 & 41 & yes & 2 & 6 & 1.5 & 75 \\
\hline 12 & Female & 30 & 41 & yes & 2 & 4 & 1 & 75 \\
\hline 13 & Male & 31 & 41 & yes & 2 & 5 & 0.5 & 90 \\
\hline 14 & Male & 43 & 31 & yes & 2 & 6 & 1 & 83.33 \\
\hline 15 & Male & 24 & 32 & yes & 1 & 3 & 0 & 100 \\
\hline
\end{tabular}

A significant difference was found in the reduction in the recession depth between the two protocols used: the average improvement in recession depth for the first protocol was $4.0 \pm 0.83 \mathrm{~mm}$ as compared to the second protocol which showed less improvement in recession depth with an average of $1.88 \pm 1.29 \mathrm{~mm}(p=0.008)$. Recession depth after surgery was significantly reduced in the first protocol $(0.66 \pm 0.60 \mathrm{~mm})$ compared to the second protocol $(2.33 \pm 0.96 \mathrm{~mm})(p=0.008)$. The first protocol showed an improvement of $87.2 \%$ as compared to the second protocol which showed an improvement of $43.8 \%(p=0.008)$.

\section{Discussion}

Tooth malposition post-orthodontic treatment leading to gingival recession is most often due to an unwanted force extracted by distortion and activation of the retainer's wire. Therefore, the first stage of resolving and treating the gingival recessions is carried out to remove the BLR by either 
the orthodontist or the periodontist. This should be followed by immediate clinical documentation that is critical for follow-up changes.

Although only 15 cases were examined in the current study, the significant improvement in Miller class III recession treatment following the protocol that included BLR removal was striking. Most of the patients have completed the orthodontic treatment as young adults (between the ages of 15 and 18 years); however, no data regarding the exact starting time of the recession, nor the changes over time could be obtained accurately. All the patients reported fast progression of the recession, which caused them great concern and encouraged them to seek treatment urgently.

The issue of BLR deformation is mostly common in flexible spiral wires, which were used for the patients in our study. It was suggested that flexible spiral wires retainers bonded on all six mandibular anterior teeth might induce unexpected movement of anterior teeth to such an extent that retreatment is necessary [21]. These unexpected movements are not considered to be a relapse, as torque differences were not present either before or at the end of orthodontic treatment. Rather, it might be the result of wire deflection during bonding or mechanical deformation in the post-treatment period [21].

We assume that the removal of the BLR allows spontaneous correction of the tooth position due to the release of undesired forces. Such movements are the result of tension changes in the periodontal and gingival fibers, changes in occlusal forces, or soft tissue pressure (cheeks versus the tongue), which are limited by the bone envelope [2]. Apparently, these position changes improve the surgical results of the perioplastic surgery and its long-term stability. In cases treated using the second protocol in which the BLR was not removed prior to the surgical intervention, unwanted forces continued to affect tooth position and caused surgical procedure failure.

It should be noted that the removal of the BLR might contribute to the improvement in oral hygiene; however, its effect on the result of the surgery is minor as the hygiene of the buccal surface is not directly affected by lingual retainer location [22].

Orthodontic correction of roots positioned outside the alveolar envelope is important to reduce gingival recessions and to provide favorable conditions to the periodontal surgery [23]. Orthodontic retreatment will enhance the surgical result; however, it can be performed only when there is enough lingual bone support [24]. If orthodontic re-treatment is not feasible and/or refused by the patient, the removal of the BLR prior to the surgical procedure might improve the surgical outcome.

In this study, we used the Miller classification that became a common approach in identifying soft tissue recessions [10]. Recently, the use of Miller's classification was reviewed and the difficulty in assignment of some recessions to a specific class was outlined [25,26]. Cairo et al. [27] suggested a new classification system of gingival recessions based on the interproximal clinical attachment level. Gingival recessions without loss of interproximal attachment were considered to be RT1 defects and with interproximal attachment loss were considered to be RT2 or RT3 defects. In the new classification by Cairo et al. [27], the malposition of the root is not considered a prognostic criterion, although it is a limiting factor for the amount of root coverage achieved at the buccal site after surgery. This may be associated with the blood supply provided by interproximal soft tissue to the buccal flap/graft during the healing process. Therefore, we find the consideration of the tooth position by Miller's classification system more suitable for post-orthodontic lower incisors recessions.

Root coverage techniques applying a CTG appear to be the gold standard [28-30], showing a high degree of root coverage with excellent esthetic results [31] both in short- and long-term follow ups [32-34].

The envelope technique, where a CTG is placed underneath a split thickness flap around the recession [35], originally described for single-tooth cases, resulting in $84 \%$ mean root coverage with complete root coverage in $61 \%$ of the sites [36,37]. Several variations to this surgical approach were suggested later on: horizontal mattress sutures to mesially and distally anchor the CTG underneath the envelope [38], muco-periosteal-mucosal tunnel where a coronally positioned flap was anchored at the contact area with mattress sutures to cover the CTG [39] and the modified microsurgical 
tunnel technique [40]. It was suggested that in the case of post-orthodontic lower incisor recessions, the modified tunnel double papilla procedure should be used to obtain maximal root coverage [41].

\section{Conclusions}

Treating Miller class III recessions in post-orthodontic patients should include the elimination of unwanted exerted forces, which affects tooth position. The removal of the bonded lingual retainer prior to the surgical procedure showed significantly greater improvement in recession depth, compared to cases in which the retainer was kept. The removal of the lingual retainer in combination with the suggested surgical technique is recommended for improving root coverage in Miller class III recessions.

Author Contributions: Conceptualization, I.B. and R.S.; methodology, A.S. and F.R.; formal analysis, R.S.; resources, I.B. and A.S.; data curation, I.B. and F.R.; writing-original draft preparation, R.S., I.B. and V.B.; supervision, I.B. and R.S. All authors have read and agreed to the published version of the manuscript.

Funding: This research received no external funding.

Acknowledgments: The authors wish to thank Ariel Pokhojaev for preparing the figures.

Conflicts of Interest: The authors declare no conflict of interest.

\section{References}

1. Al Yami, E.A.; Kuijpers-Jagtman, A.M.; van 't Hof, M.A. Stability of orthodontic treatment outcome: Follow-up until 10 years postretention. Am. J. Orthod. Dentofac. Orthop. 1999, 115, 300-304. [CrossRef]

2. Littlewood, S.J.; Kandasamy, S.; Huang, G. Retention and relapse in clinical practice. Aust. Dent. J. 2017, 62, 51-57. [CrossRef]

3. Littlewood, S.J.; Millett, D.T.; Doubleday, B.; Worthington, H.V. Retention procedures for establishing tooth position after treatment with orthodontic braces. Cochrane Database Syst. Rev. 2016, 51, 1-135. [CrossRef]

4. Andriekute, A.; Vasiliauskas, A.; Sidlauskas, A. A survey of protocols and trends in orthodontic retention. Prog. Orthod. 2017, 18, 31. [CrossRef] [PubMed]

5. Padmos, J.A.; Fudalej, P.S.; Renkema, A.M. Epidemiologic study of orthodontic retention procedures. Am. J. Orthod. Dentofac. Orthop. 2018, 153, 496-504. [CrossRef]

6. Iliadi, A.; Kloukos, D.; Gkantidis, N.; Katsaros, C.; Pandis, N. Failure of fixed orthodontic retainers: A systematic review. J. Dent. 2015, 43, 876-896. [CrossRef]

7. Roussarie, F.; Douady, G. A side-effect of bonded retention wires: The "wire syndrome": Part 1. J. Dentofac. Anom. Orthod. 2016, 19, 106. [CrossRef]

8. Shaughnessy, T.G.; Proffit, W.R.; Samara, S.A. Inadvertent tooth movement with fixed lingual retainers. Am. J. Orthod. Dentofac. Orthop. 2016, 149, 277-286. [CrossRef]

9. Adams, D.F. The American Academy of Periodontology. J. Periodontol. 1996, 67, 177-179. [CrossRef]

10. Miller, P.D. A classification of marginal tissue recession. Int. J. Periodontics Restor. Dent. 1985, 5, 8-13.

11. Tatakis, D.N.; Chambrone, L.; Allen, E.P.; Langer, B.; McGuire, M.K.; Richardson, C.R.; Zabalegui, I.; Zadeh, H.H. Periodontal Soft Tissue Root Coverage Procedures: A consensus report from the AAP regeneration workshop. J. Periodontol. 2015, 86, S52-S55. [CrossRef] [PubMed]

12. Melsen, B.; Allais, D. Factors of importance for the development of dehiscences during labial movement of mandibular incisors: A retrospective study of adult orthodontic patients. Am. J. Orthod. Dentofac. Orthop. 2005, 127, 552-561. [CrossRef] [PubMed]

13. Kamak, G.; Kamak, H.; Keklik, H.; Gurel, H.G. The effect of changes in lower incisor inclination on gingival recession. Sci. World J. 2015, 2015, 193206. [CrossRef] [PubMed]

14. Wahab, R.F.; Oktawati, S.; Mappangara, S. Gingival recession of mandibular incisor post-orthodontic treatment: A systematic review. MDJ 2020, 9, 118-120.

15. Pazera, P.; Fudalej, P.; Katsaros, C. Severe complication of a bonded mandibular lingual retainer. Am. J. Orthod. Dentofac. Orthop. 2012, 142, 406-409. [CrossRef]

16. Renkema, A.M.; Fudalej, P.S.; Renkema, A.; Kiekens, R.; Katsaros, C. Development of labial gingival recessions in orthodontically treated patients. Am. J. Orthod. Dentofac. Orthop. 2013, 143, 206-212. [CrossRef] 
17. Cairo, F.; Rotundo, R.; Miller, P.D.; Prato, G.P.P. Root Coverage Esthetic Score: A System to Evaluate the Esthetic Outcome of the Treatment of Gingival Recession Through Evaluation of Clinical Cases. J. Periodontol. 2009, 80, 705-710. [CrossRef]

18. Stefanini, M.; Jepsen, K.; de Sanctis, M.; Baldini, N.; Greven, B.; Heinz, B.; Wennström, J.; Cassel, B.; Vignoletti, F.; Sanz, M.; et al. Patient-reported outcomes and aesthetic evaluation of root coverage procedures: A 12-month follow-up of a randomized controlled clinical trial. J. Clin. Periodontol. 2016, 43, 1132-1141. [CrossRef]

19. Mounssif, I.; Stefanini, M.; Mazzotti, C.; Marzadori, M.; Sangiorgi, M.; Zucchelli, G. Esthetic evaluation and patient-centered outcomes in root-coverage procedures. Periodontology 2000 2018, 77, 19-53. [CrossRef]

20. Hürzeler, M.B.; Weng, D. A single-incision technique to harvest subepithelial connective tissue grafts from the palate. Int. J. Periodontics Restor. Dent. 1999, 19, 279-287.

21. Katsaros, C.; Livas, C.; Renkema, A.M. Unexpected complications of bonded mandibular lingual retainers. Am. J. Orthod. Dentofac. Orthop. 2007, 132, 838-841. [CrossRef] [PubMed]

22. Pandis, N.; Vlahopoulos, K.; Madianos, P.; Eliades, T. Long-term periodontal status of patients with mandibular lingual fixed retention. Eur. J. Orthod. 2007, 29, 471-476. [CrossRef] [PubMed]

23. Laursen, M.G.; Rylev, M.; Melsen, B. The role of orthodontics in the repair of gingival recessions. Am. J. Orthod. Dentofac. Orthop. 2020, 157, 29-34. [CrossRef]

24. Chaushu, S.; Stabholz, A. Orthodontic-associated localized gingival recession of lower incisors: Who should treat it? Compend. Contin. Educ. Dent. 2013, 34, 6-12. [PubMed]

25. Mahajan, A. Mahajan's modification of miller's classification for gingival recession. Dent. Hypotheses 2010, 1, 45-50. [CrossRef]

26. Pini-Prato, G. The Miller classification of gingival recession: Limits and drawbacks. J. Clin. Periodontol. 2011, 38, 243-245. [CrossRef]

27. Cairo, F.; Nieri, M.; Cincinelli, S.; Mervelt, J.; Pagliaro, U. The interproximal clinical attachment level to classify gingival recessions and predict root coverage outcomes: An explorative and reliability study. J. Clin. Periodontol. 2011, 38, 661-666. [CrossRef]

28. Roccuzzo, M.; Bunino, M.; Needleman, I.; Sanz, M. Periodontal plastic surgery for treatment of localized gingival recessions: A systematic review. J. Clin. Periodontol. 2002, 29, 178-194. [CrossRef]

29. Chambrone, L.; Chambrone, D.; Pustiglioni, F.E.; Chambrone, L.A.; Lima, L.A. Can subepithelial connective tissue grafts be considered the gold standard procedure in the treatment of Miller Class I and II recession-type defects? J. Dent. 2008, 36, 659-671. [CrossRef]

30. Chambrone, L.; Sukekava, F.; Araújo, M.G.; Pustiglioni, F.E.; Chambrone, L.A.; Lima, L.A. Root-Coverage Procedures for the Treatment of Localized Recession-Type Defects: A Cochrane Systematic Review. J. Periodontol. 2010, 81, 452-478. [CrossRef]

31. Greenwell, H.; Bissada, N.F.; Henderson, R.D.; Dodge, J.R. The Deceptive Nature of Root Coverage Results. J. Periodontol. 2000, 71, 1327-1337. [CrossRef]

32. Langer, B.; Langer, L. Subepithelial Connective Tissue Graft Technique for Root Coverage. J. Periodontol. 1985, 56, 715-720. [CrossRef]

33. Nemcovsky, C.E.; Artzi, Z.; Tal, H.; Kozlovsky, A.; Moses, O. A Multicenter Comparative Study of Two Root Coverage Procedures: Coronally Advanced Flap with Addition of Enamel Matrix Proteins and Subpedicle Connective Tissue Graft. J. Periodontol. 2004, 75, 600-607. [CrossRef]

34. Moses, O.; Artzi, Z.; Sculean, A.; Tal, H.; Kozlovsky, A.; Romanos, G.E.; Nemcovsky, C.E. Comparative Study of Two Root Coverage Procedures: A 24-Month Follow-Up Multicenter Study. J. Periodontol. 2006, 77, 195-202. [CrossRef]

35. Raetzke, P.B. Covering Localized Areas of Root Exposure Employing the "Envelope" Technique. J. Periodontol. 1985, 56, 397-402. [CrossRef]

36. Allen, A.L. Use of the supraperiosteal envelope in soft tissue grafting for root coverage. I. Rationale and technique. Int. J. Periodontics Restor. Dent. 1994, 14, 216-227. [CrossRef]

37. Allen, A.L. Use of the supraperiosteal envelope in soft tissue grafting for root coverage. II. Clinical results. Int. J. Periodontics Restor. Dent. 1994, 14, 302-315.

38. Zabalegui, I.; Sicilia, A.; Cambra, J.; Gil, J.; Sanz, M. Treatment of multiple adjacent gingival recessions with the tunnel subepithelial connective tissue graft: A clinical report. Int. J. Periodontics Restor. Dent. 1999, 19, 199-206. 
39. Azzi, R.; Etienne, D.; Carranza, F. Surgical Reconstruction of the Interdental Papilla. Int. J. Periodontics Restor. Dent. 1998, 18, 467-473. [CrossRef]

40. Zuhr, O.; Fickl, S.; Wachtel, H.; Bolz, W.; Hürzeler, M.B. Covering of gingival recessions with a modified microsurgical tunnel technique: Case report. Int. J. Periodontics Restor. Dent. 2007, 27, 457-463. [CrossRef]

41. Sebaoun, A.; Nemcovsky, C.; Beitlitum, I.; Moses, O. Modified Tunnel Double Papilla Procedure for Root Coverage in the Anterior Mandible. Int. J. Periodontics Restor. Dent. 2019, 39, 503-509. [CrossRef] [PubMed]

Publisher's Note: MDPI stays neutral with regard to jurisdictional claims in published maps and institutional affiliations.

(C) 2020 by the authors. Licensee MDPI, Basel, Switzerland. This article is an open access article distributed under the terms and conditions of the Creative Commons Attribution (CC BY) license (http://creativecommons.org/licenses/by/4.0/). 